\title{
Child development: analysis of a new concept ${ }^{1}$
}

\author{
Juliana Martins de Souza² \\ Maria de La Ó Ramallo Veríssimo
}

\begin{abstract}
Objectives: to perform concept analysis of the term child development (CD) and submit it to review by experts. Method: analysis of concept according to the hybrid model, in three phases: theoretical phase, with literature review; field phase of qualitative research with professionals who care for children; and analytical phase, of articulation of data from previous steps, based on the bioecological theory of development. The new definition was analyzed by experts in a focus group. Project approved by the Research Ethics Committee. Results: we reviewed 256 articles, from 12 databases and books, and interviewed 10 professionals, identifying that: The CD concept has as antecedents aspects of pregnancy, factors of the child, factors of context, highlighting the relationships and child care, and social aspects; its consequences can be positive or negative, impacting on society; its attributes are behaviors and abilities of the child; its definitions are based on maturation, contextual perspectives or both. The new definition elaborated in concept analysis was validated by nine experts in focus group. It expresses the magnitude of the phenomenon and factors not presented in other definitions. Conclusion: the research produced a new definition of $\mathrm{CD}$ that can improve nursing classifications for the comprehensive care of the child.
\end{abstract}

Descriptors: Child Development; Concept Formation; Nursing Diagnosis; Classification; Pediatric Nursing.

\footnotetext{
1 Paper extracted from doctoral dissertation "Child development: concept analysis and NANDA-I's diagnoses review", presented to Escola de Enfermagem, Universidade de São Paulo, São Paulo, SP, Brazil. Supported by Fundação de Amparo à Pesquisa do Estado de São Paulo (FAPESP), Brazil, process \# 2011/51012-3.

2 PhD, Assistant Professor, Departamento de Enfermagem, Universidade Federal de Goiás, Catalão, GO, Brazil.

3 PhD, Professor, Escola de Enfermagem, Universidade de São Paulo, São Paulo, SP, Brazil.
}

Corresponding Author:

Juliana Martins de Souza

Universidade Federal de Goiás. Departamento de Enfermagem

Av. Dr. Lamartine Pinto de Avelar, 1120

Setor Universitário

CEP: 75704-020, Catalão, GO, Brasil

E-mail: jumartins2005@gmail.com
Copyright @ 2015 Revista Latino-Americana de Enfermagem This is an Open Access article distributed under the terms of the Creative Commons Attribution Non-Commercial License (CC BY-NC).

This license lets others distribute, remix, tweak, and build upon your work non-commercially, and although their new works must also acknowledge you and be non-commercial, they don't have to license their derivative works on the same terms. 


\section{Introduction}

Child Development (CD) is a fundamental part of human development, emphasizing that the brain architecture is shaped in the first years, from the interaction of genetic inheritance and influences of the environment in which the child lives ${ }^{(1-2)}$.

To promote the health of children, it is essential to understand their peculiarities, as well as environmental conditions favorable to their development(3). The understanding of caregivers about the characteristics and needs of children, as a result of their development process, promotes the integral development, because daily care is the major space for the promotion of $\mathrm{CD}^{(3)}$.

A valuable resource to the nurse performs their job facing all aspects of child development is the Systematization of Nursing Care. It proposes the use of the nursing classifications, standardizing the language used in assisting individuals, families and communities in different settings ${ }^{(4)}$. However, for use the nursing classifications in a plan of quality care in the approach of the $C D$, it is necessary that they address the entire complexity of this phenomenon.

A theoretical study of NANDA-International (NANDA-I) and of the International Classification for Nursing Practice $\left(\right.$ ICNP $\left.^{\circledR}\right)$, which are the most disseminated classifications, found important limitations about the approach of $C^{(5)}$. NANDA-I aims to conduct the language standardization of nursing diagnoses ${ }^{(6)}$. ICNP ${ }^{\circledR}$ intends to be an unifying mark of nursing terminologies, and it was recognized by the World Health Organization (WHO) as a member of the Family of International Classifications $^{(7)}$.

NANDA-I has real and risk diagnostics for CD, but there is no promotion diagnostics; these cover the development and growth in a single diagnosis, although they are separate phenomena, with different features and definitions and subject to various interventions ${ }^{(5)}$.

In ICNP, there are several focus terms related to the child development phenomenon, but these terms do not explain it. The focus terms growth and development are defined as separate terms, but their descriptions are confusing, mixing the two concepts ${ }^{(5)}$.

When considering the limitations of the $C D$ approach in the two studied classifications, it is possible to suppose a few reasons why the topic has not yet been better studied in both classifications. One of them is the prioritization of biological aspects in health care, with few instruments and approaches that support promotion actions. In this sense, the development of the child is rarely observed in health care ${ }^{(8-9)}$. In addition, CD is a broad and complex process, better clarified in recent decades, including its relationship with the daily care and the influence of the environment on $\mathrm{it}^{(1)}$.

Thus, the difficulties in having nursing diagnoses related to $C D$ can occur in the absence of an approach that encompasses the complexity of the term and the absence of a concept to support the specificity of nursing in the child health. Therefore, it is essential to perform the analysis of the CD concept, to subsidize the classifications of nursing diagnoses and provide diagnostics that enable the development of care plans aimed to $C D$.

This research aimed to perform the concept analysis of the term child development and analyze the new definition proposed as a product of the concept analysis.

\section{Method}

The concept analysis aims to clarify, recognize and define concepts that describe nursing phenomena, in order to promote understanding. The clarification of a certain concept contributes to the knowledge construction of the area(10).

The hybrid model of concept development was used in this research. It considers three interconnected stages for the development of the concept: theoretical phase, field phase and analytical phase ${ }^{(11)}$. In each one of the stages, the four categories of concept analysis must be composed of: attributes, antecedents, consequences and concept definition.

The theoretical phase corresponds to the study of literature. Since CD is a subject of study in several disciplines, it was important to consult databases which comprised other areas besides health, such as education, behavioral sciences and social sciences. Ten databases and two information portals for research were selected with expert support in information science: BVS, Lilacs, Cochrane Library, Cinahl, Pubmed, Francis, Edubase, Eric, Psycinfo, IndexPsi, Scopus and Web Of Science. Later, textbooks of pediatric nursing were consulted to contemplate some aspects of the concept that the articles from databases did not present.

Child Development and its corresponding descriptors were used, and limits that could ensure the comprehensiveness of the theme and reliability on clipping were established, reducing the number of studies to a viable volume: year of publication - 2011 and 2012; language - Portuguese, English and Spanish; and age group - under 1 year. Search issues followed 
the model of concept analysis. To set the antecedents of $C D$, we researched: What factors influence $C D$ ? To establish its attributes, the question was: What are the characteristics of $C D$ ? To find its consequences, the question was: What are the consequences of adequate $C D$ and inadequate $C D$ ? And for its definition, the question was: What is $C D$ ?

The field phase consists of research with subjects of the practice who work with the phenomenon under study. Qualitative research was carried out, with semistructured interviews with professionals working with child development in five municipalities of the state of São Paulo, Brazil, and who participated in earlier $C D$ trainings, for being potentially interested in the subject and work in professional activities related to promotion of $\mathrm{CD}$. The interviews followed the same issues of the bibliographic search. The data recorded and transcribed were subjected to content analysis, according to pre-established categories on hybrid method of concept analysis.

The analytical phase was the articulation of the results of theoretical and field stages and allowed the characterization of the concept components more broadly, as well as the elaboration of a definition of the CD term.

The CD definition elaborated was subjected to review by experts. Although the hybrid model does not propose this step, it was considered that it would give greater consistency to the concept created. To facilitate and intensify the discussion, we decided to perform the analysis of the definition of the concept in a focus group.

The experts were located from a group of people registered in the database of the research group Health Care and Child's Development Promotion, of the School of Nursing at the University of São Paulo, for being considered potential collaborators and meeting the selection criteria. The invitation to take part in the focus group was sent to 30 people who met the inclusion criteria: work with child health for over three years and be an expert, master or doctor in the area of child health. To encourage the participation of professionals outside São Paulo, the focus group was planned for the same day of other event of the research group, aiming to optimize the cost of transportation, since there would be no reimbursement of expenses for participants. The discussion was recorded and transcribed to support the description of the results.

The project was approved by the Research Ethics Committee of the School of Nursing at the University of
São Paulo (protocol CEP 0114.0.196000-11), and all the participants signed a Free and Informed Consent Term.

The results were discussed according to the Bioecological Theory of Human Development(12-13), composed of four interconnected elements: processperson-context-time. The development process involves the relationship between the individual and context, considers all interactions and conditions of these interactions with any implication for the development of the human being; the person is considered with all biological, cognitive, behavioral and emotional characteristics; the context refers to all environments that influence development; and the time involves the issues of temporality, constituting the cronosystem that suppress the changes throughout life ${ }^{(13)}$. The context is comprised in a broadened form, composed of: microsystem, which includes the nearest environments in which the child lives; mesosystem, which includes interaction of microsystems in which the child is present; exosystems, the environments in which the child is not inserted, but that affect their development, as the work of parents; and macrosystem, which encompasses social and cultural structures and socioeconomic conditions ${ }^{(12-13)}$.

\section{Results}

In the theoretical phase, 256 articles that met the criteria were selected and classified according to the four categories of concept analysis: concept antecedents (228 studies), concept attributes (5 studies), concept consequences (32 studies) and concept definition (23 studies). Of the 256 articles analyzed, only 12 were Brazilian. Most articles (210) were published in the year of 2011 and 46 were published until April 2012. Publishing journals were very varied, only two articles were published in journals in the nursing field, three in education, 16 in journals of child development, 23 in journals about human development, 29 in behavioral sciences and 183 in journals in the health area - 80 of these specific to pediatrics.

Six nurses, two pedagogues, one psychologist and one social worker attended the field phase; all were women, with an average age of 42.2 years. Half the participants had more than 10 years and three more than 25 years of academic completion. The time of work with child care ranged from two to more than 20 years.

The category antecedents of the concept was composed of factors related to $C D$ found in literature and in the talks of professionals, not differing in 
content (Figure 1). Theoretical and field phases were complementary, since sometimes the talk of professionals was more generic, but brought additional data to literature.

The category attributes of the concept demonstrates the characteristics present when the concept occurs, and such characteristics were verified both in the literature and field research, as the range of abilities in various development areas (Figure 1). Searching the literature, few studies have addressed these abilities and they focused on evaluation and analysis of the achievement of certain abilities, such as language, to walk, pincer grasp and cognitive development, and was therefore necessary to complement the content by searching in textbooks about the major theories of CD.

Scholars and theorists whose studies are widely used in the CD approach, as Sigmund Freud, Erik Erikson and Jean Piaget explained the development in stages according to the approximate age, describing the characteristics of behavior or abilities of various areas of development, such as motor, cognitive, and emotional(14-15). We concluded that such areas are the characteristics or attributes of development, so it is by the observation of behaviors and abilities in the areas of development that the course of development of the child can be verified.
For the category concept consequences, we selected articles that addressed evaluations of long term CD or in higher age groups, such as school children and teenagers. There were formed two sets of consequences: those relating to adequate $C D$ and those relating inadequate $C D$. The interviews adressed the same two sets of consequences and the same topics (Figure 1).

In the category definition of the concept, initially, we grouped articles that discussed more conceptual factors. However, we observed, both in these and in other studied articles, that there were no new definitions to the term child development, once they based on classical definitions of scholars to development. Seeking more data about the concept definition, we revised the main approaches of the development and principal authors of reference on the subject (14-15).

Figure 1 summarizes the analytical phase of the study, of articulation between the data of the field and theoretical phases. The category antecedents is indicated by the connective "is influenced by"; the category attributes is indicated by the connective "is characterized by"; the category consequences is indicated by the connectives "when adequate leads to" and "when inadequate leads to"; and the category definition is indicated by the connective "is defined as".

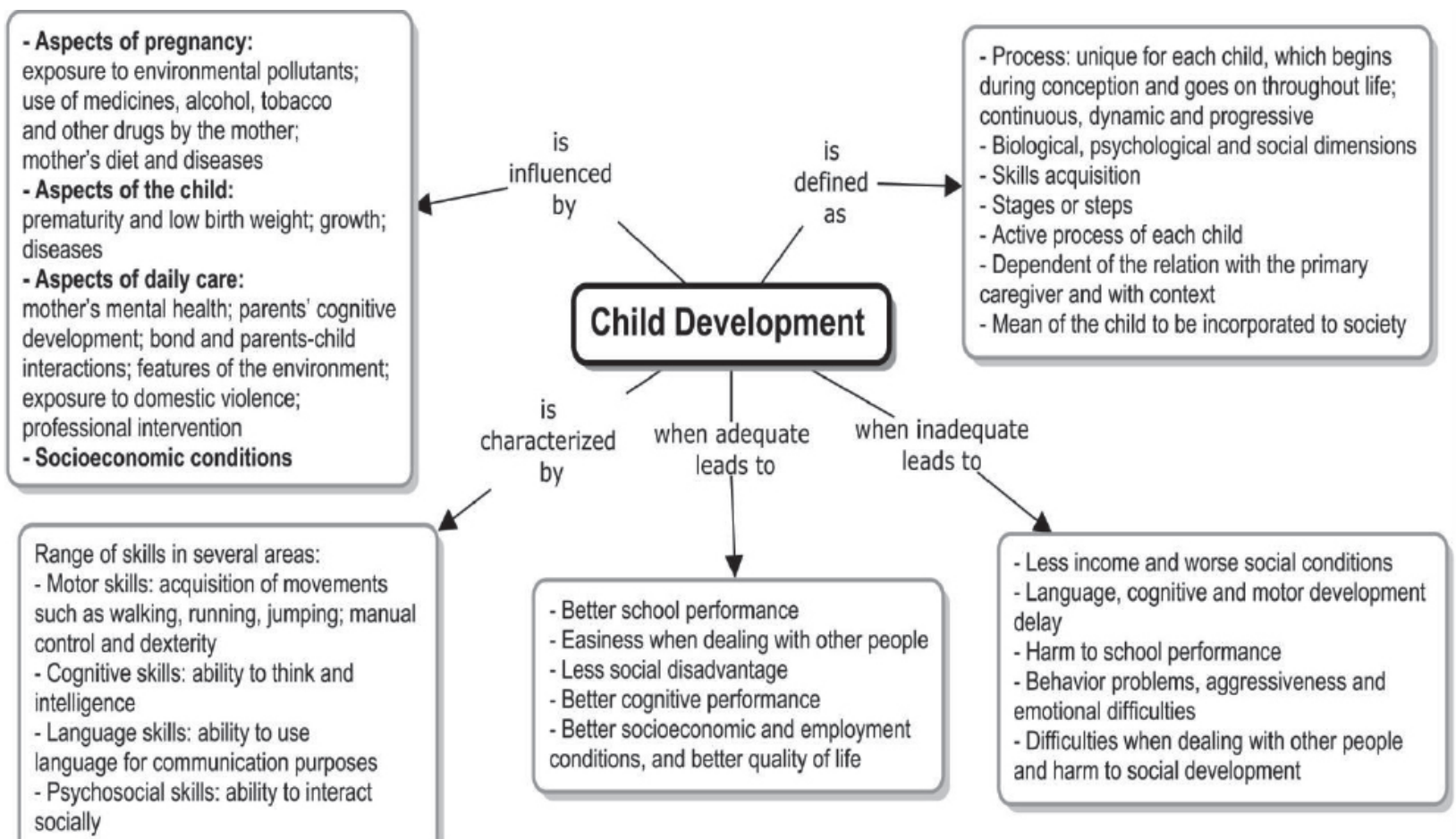

Figure 1 - Concept map with the results of the concept analysis of the term child development, according to the hybrid model 
As a product of the concept analysis, according to the hybrid model, the following definition of the term child development was elaborated:

"Child development is part of human development, a unique process of each child that aims to insert him/ her in the society where he/she lives. It is expressed by continuity and changes in motor, psychosocial, cognitive and language abilities, with progressively more complex acquisitions in the daily life functions. The prenatal period and the first years of life are the foundation of this process, which arises from the interaction of biopsychological characteristics genetically inherited, and experiences offered by the environment. The experiences are constituted by the care that the child receives and the opportunities that the child has to actively exercise his/hers abilities. The care aimed at the needs of development enables the child to reach full potential at every stage of development, with positive repercussions in adult life"(16)

This definition was submitted to the analysis of a group of experts. The focus group had nine participants, besides the researcher who coordinated the group, and her mentor as an observer. Seven nurses, one doctor and one physical therapist participated. There were people from the states of: São Paulo (five), Minas Gerais (two) and Paraná (two). They concluded their undergraduate courses from six to 30 years, but most of them (seven) had from 5 to 15 years of experience. As to professional qualification, one participant had specialization in the area of Neonatal and Pediatric Intensive Care and Public Health Management; two had specialization and master's degree; one had specialization, master's and doctoral degrees; and five had master's degree. Seven participants had publications in the pediatrics area.

The group considered that the definition should be more concise, highlighting child development as fundamental to human development, the active role of children in the development process and care as a key element for the promotion of child development. The considerations on the definition of the concept were compatible with the results of the concept analysis, but we realize that they had not been properly incorporated in the first definition proposal.

The definition was rewritten as:

"Child development is a fundamental part of human development, an active and unique process for each child, expressed by continuity and changes in motor, psychosocial, cognitive and language abilities, with acquisitions progressively more complex in the functions of daily life and in the exercise of their social role. The prenatal period and the first years of child life are crucial in the development process, which is constituted by the interaction of biopsychological characteristics genetically inherited, and experiences offered by the environment. The achievement of the potential of every child depends on the care responsive to their needs of development"(16).

\section{Discussion}

The results of the concept analysis showed the incorporation of knowledge consistent with the bioecological theory, both in analyzed studies and in the interviews, as pointed out in this discussion, which was structured according to the four elements of the theory process-person-context-time(13).

In relation to the process, the interactions of the child, recognized as a central component of development, have achieved great prominence in the field phase. In the theoretical phase, studies that analyzed the bond and the interaction of the parents with the child also showed this relationship. However, we observed in the two data sets an emphasis on the role of caregivers and less emphasis on the active role of the child in the interactions with people, objects and symbols present in their immediate environment, as is highlighted by the bioecological theory.

Interaction is crucial to development. When relationships are imbued with affection, they allow the formation of a bond that will continue to exist, even when these individuals are not together, being fundamental to the child in the establishment of relations in other social contexts beyond the familiar environment ${ }^{(13)}$.

Still concerning the process, the characteristics of caregivers, especially their mental health, directly affect their interaction with the child. In this sense, the role of the professional can be a factor of support to assist in improving this relationship.

A second element of the bioecological theory is the person, considering his/her biopsychological characteristics and those built when interacting with the environment ${ }^{(12)}$. In the bioecological model, the characteristics of the person are both producers and products of development, because they are one of the elements that influence the form, content and direction of the proximal processes. The person is in the center of the ecological system ${ }^{(12)}$.

For the professionals who participated in this study, it seems that environmental aspects supersede 
the individual, since they stood out. Intrinsic factors of the child were cited in the field phase as factors influencing $C D$, but with superficial narratives; in the theoretical phase many studies showed the influence of prematurity and low birth weight, child nutrition, growth and diseases.

In relation to the context, the environment in which the child is inserted had highlights in the theoretical and field phases, in line with Bronfenbrenner, who stresses the importance of the environment in the context, dividing it into mesosystem, microsystem, exosystem and macrosystem(12-13). In this study, the factors cited as influential for child development are parts of all these systems:

- Microsystem: evidenced in the family environment and in some studies in shelters. The importance of the bond, parental interaction with the child and features of the environment in which the child lives were also highlighted;

- Mesosystem: the influence of environments in which the child in development is inserted, such as day nurseries, was identified in several studies and in professionals' statements;

- Exosystem: the relationship between exosystem and development was not referred to directly in the field phase. We did not find studies in the theoretical phase that referred to this focus. However, it is possible to identify the existence of this level, although not explained, when considered the influence of interactions, since the exosystems directly influence these relationships, as an event in the work of parents or school of the brothers which reverberate in the microsystem and existing relations;

- Macrosystem: some studies and professionals' statements point out the broader structure factors that influence development, such as socioeconomic and cultural conditions.

The fourth element of the theory (time) showed up in the results as the data referred to a development process that does not occur instantly during children's interactions and experiences, but are being built in their life time. The two sets of data mentioned only the individual development processes, without referring to the idea of continuities and changes in the development of children that could be identified as products of sociohistorical changes between generations.

All aspects of the process, context and person can be classified as protectors, when offering favorable influences to $C D$ or as a risk or vulnerability to $C D$, when their influences are potentially harmful. Therefore, all these aspects should be the focus of attention in public policies and in social and community practices.

To cover the search results, the proposed definition incorporated factors that are not explored in other definitions, such as mention children as active in their development and care as a central element of this process. This definition is compatible with the bioecological theory of development, because it presents the concept of person in development, environment and interaction between them, and also evidences the four theory elements: process, person, context and time, as follows.

- Process: explicit throughout the concept, emphasizing the importance of care aimed at the needs of development; is related to interactions, bonds, and affection, stressing the importance of the experiences of the child.

- Context: all levels of context are considered essential because they determine child's experiences and the care they receive; includes family and other environments that will share this care and experiences.

- Person: development is an unique process for each child, of continuity and changes of motor, psychosocial, cognitive and language abilities, and of biopsychological characteristics, genetically inherited.

- Time: the definition presents research findings from neuroscience and contemporary researches for child development as a fundamental part of human development, highlighting the prenatal period and the first years of life as a milestone of this process. The definition of the concept reflects current science.

Thus, this definition may subsidize nursing classifications in the elaboration of diagnoses, interventions and outcomes related to child development.

It is important to stress that the choice of the focus group as a technique for performing the analysis by experts was crucial, because it provided discussion among experts and immediate result, without requiring new steps of data analysis and re-evaluation by the experts, which is observed in the literature as a difficulty of methods that require several steps of analysis(17). The experience of the participants in the research and academic writing, whether in graduate studies or guidance of students of undergraduate research, in their role as teachers, favored the discussion of the concept presented, achieving great depth of analysis.

It is possible to point out as a limitation of this study the need to delimit the search time on literature review for a year, but by observing the quality of the 
results obtained, it was considered that there were no losses and, therefore, the search expansion for this research was not considered. The inclusion of textbooks to compose the attributes and definitions of the concept could also be limiting, however, criteria were used for choice of references, assuring the content quality.

The selection of subjects involved in the $C D$ training project of the municipalities was important because, for the concept analysis, it is crucial that participants have extensive experience in the matter. However, it can be one of the limitations of the study, since the statements incorporated knowledge covered during training, and research with professionals with other experiences may differ.

\section{Conclusion}

The performance of concept analysis, according to the hybrid model, was crucial for the elaboration of a concept that took into account the complexity of the phenomenon, since data from the literature review and field phase were complementary and demonstrated the incorporation of updated knowledge among professionals. Such analysis, in addition to the expert analysis, contributed to the construction of a concept applicable in practice, because, when presenting the development as a result of the interaction of the child with the environment and the relationships existing therein. This will subsidize the revision of nursing diagnoses and the appropriate selection of actions to promote $C D$, a fundamental aspect to the actions of the nurse in monitoring the health of the child.

\section{References}

1. Mustard JF. EarlyHumanDevelopment - Equityfromthe Start - LatinAmerica. Rev Latino Am Cienc Soc Niñez. $2009 ; 7(2): 639-80$.

2. Shonkoff JP, Wood DL, Dobbins MI, Earls MF, Garner AS, McGuinn L, et al. The Lifelong Effects of Early Childhood Adversity and Toxic Stress. Pediatrics. 2012;129(1):232-46.

3. Mello DF, Henrique NCP, Pancieri L, Veríssimo MLÓR, Tonete VLP, Malone M. Childs afety from the perspective of essential needs. Rev. Latino-Am. Enfermagem 2014 July-Aug;22(4):604-10.

4. Peres HHC, Lima AFC, Oliveira NB. Implementação do diagnóstico de enfermagem no registro eletrônico de saúde. In: NANDA - International. PRONANDA Programa de Atualização em Diagnósticos de Enfermagem - Conceitos Básicos. Porto Alegre: Artmed Panamericana; 2013. p. 63-84.

5. Souza JM, Veríssimo MLOR. Child Development in the NANDA-I and International Classification for Nursing Practices Nursing Classifications. Int J Nurs Knowledge 2013;24:44-8.

6. Herdman TH. Diagnósticos de enfermagem e sua relação com o raciocinio clínico. In: NANDA International. PRONANDA - Programa de Atualização em Diagnósticos de Enfermagem - Conceitos Básicos. Porto Alegre: Artmed Panamericana; 2013. p. 29-62.

7. Cubas MR, Silva SH, Rosso M. Classificação Internacional para a Prática de Enfermagem (CIPE): uma revisão de literatura. Rev Eletr Enferm. [Internet]. 2010 [acesso 20 jun 2011];12(1):186-94. Disponível em: http:/www.fen.ufg.br/revista/v12/n1/v12n1a23.htm

8. Oliveira FFS, Oliveira ASS, Lima LHO, Marques MB, Felipe GF, Sena IVO. Consulta de puericultura realizada pelo enfermeiro na estratégia de saúde da família. Rev Rene. 2013;14(4):694-703

9. Baratieri T, Soares LG, Botti ML, Campanini AC. Consulta de enfermagem em puericultura: um enfoque nos registros de atendimentos. Rev Enferm UFSM. janmar 2014;4(1):206-16

10. Bousso RS, Poles K, Cruz DALM. Conceitos e Teorias na Enfermagem. Rev Esc EnfermUSP 2014;48(1):144-8. 11. Schwartz-Barcott D, Kim HS. An expansion and elaboration of the Hybrid Model of concept development. In: Rodgers BL, Knafl KA. Concept development in nursing: foundations, techniques and applications. 2.ed. New York: Saunders -Elsevier; 2000. p. 129-59.

12. Bronfenbrenner $U$. Morris PA. The bioecological model of human development. In: Damons W, Lerner RM, editors. Handbook of child psychology. 6.ed. New York: Wiley; 2006. p. 793-828.

13. Bronfenbrenner U. Bioecologia do desenvolvimento humano. Tornando os seres humanos mais humanos. Porto Alegre: Artmed; 2011.

14. Bee $H$, Boyd D. A criança em desenvolvimento. 12ed. Porto Alegre: Artmed; 2011.

15. Berger KS. O desenvolvimento da pessoa: da infância à terceira idade. Rio de Janeiro: LTC; 2011.

16. Souza JM. Desenvolvimento infantil: análise de conceito e revisão dos diagnósticos da NANDA-I [tese]. São Paulo: Escola de Enfermagem da Universidade de São Paulo; 2014. 
17. Backes DS, Colomé JS, Erdmann RH, Lunardi VL. Grupo focal como técnica de coleta e análise de dados em pesquisas qualitativas. O Mundo da Saúde. $2011 ; 35(4): 438-42$. 